\title{
Comment on: "The measurement of tropospheric OH radicals by laser-induced fluorescence spectroscopy during the POPCORN field campaign" by Hofzumahaus et al. and "Intercomparison of tropospheric $\mathrm{OH}$ radical measurements by multiple folded long-path laser absorption and laser induced fluorescence" by Brauers et al.
}

\author{
E. J. Lanzendorf, T. F. Hanisco, N. M. Donahue and P. O. Wennberg \\ Department of Chemistry, Harvard University, Cambridge, MA.
}

Calibration of laser induced fluorescence (LIF) instruments that measure $\mathrm{OH}$ is challenging because it is difficult to reliably introduce a known amount of this reactive radical into a measurement apparatus. In a recent paper, Hofzumahaus et al., [1996] describe a novel and seemingly simple technique to accomplish this goal: they dissociate trace quantities of water vapor in air with a low pressure mercury $(\mathrm{Hg})$ lamp to produce low concentrations $\left(10^{5}-10^{9} \mathrm{~cm}^{-3}\right)$ of $\mathrm{OH}(\mathrm{R} 1)$. The lamp fluence is then calibrated by ozone actinometry (R2):

$$
\begin{gathered}
\mathrm{H}_{2} \mathrm{O}+\mathrm{h} v(1849.5 \AA) \\
\mathrm{O}_{2}+\mathrm{h} v(1849.5 \AA) \\
\mathrm{O}+\mathrm{O}_{2} \rightarrow \mathrm{O}_{3} .
\end{gathered}
$$

The $\mathrm{OH}$ concentration is inferred from the ambient water vapor and $\mathrm{O}_{2}$ mixing ratios, the measured $\mathrm{O}_{3}$ concentration, and the relevant cross sections:

$$
[\mathrm{OH}]=\frac{\sigma_{\mathrm{H}_{2} \mathrm{O}}\left[\mathrm{H}_{2} \mathrm{O}\right]\left[\mathrm{O}_{3}\right]}{2 \sigma_{\mathrm{O}_{2}}\left[\mathrm{O}_{2}\right]} .
$$

In Brauers et al., [1996], an $\mathrm{OH}$ measurement calibrated with this technique was compared with an $\mathrm{OH}$ measurement by differential optical absorption spectroscopy (DOAS) [Dorn et al., 1996]. Excellent agreement (within 1\%) was obtained, leading the authors to conclude that the agreement "is even better than what is expected from the estimated accuracies

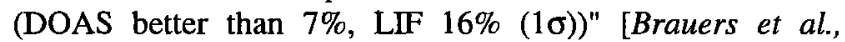
1996]. This LIF calibration technique is also used by others and has been discussed in the literature [Aschmutat et al., 1994, Reiner et al., 1997, Schultz et al., 1996].

Accurate absorption cross sections for $\mathrm{O}_{2}$ and $\mathrm{H}_{2} \mathrm{O}$ at the $1849.5 \AA \mathrm{Hg}$ emission wavelength are required to infer the $\mathrm{OH}$ density from the measured $\mathrm{O}_{3}$ and $\mathrm{H}_{2} \mathrm{O}$ concentration. In the studies described above the cross sections were taken from the literature: the $\mathrm{H}_{2} \mathrm{O}$ cross section $\left(\sigma_{\mathrm{H}_{2} \mathrm{O}}\right)$ from $\mathrm{Hudson}$ and Kieffer, [1975]; the oxygen cross section $\left(\sigma_{\mathrm{O}_{2}}\right)$ from Washida et al., [1971]. The measurement by Washida et al. is difficult to interpret because the absorption coefficients are given in units of $\left(\mathrm{atm}^{-1} \times \mathrm{cm}^{-1}\right)$ without discussion of base or temperature. The actual value is $2.2 \times 10^{-20} \mathrm{~cm}^{2} / \mathrm{molec}(\mathrm{N}$. Washida personal communication, 1997). This is 2.3 times larger than the value used by Hofzumahaus et al., [1996]. Thus, the agreement between the LIF and DOAS

Copyright 1997 by the American Geophysical Union. measurements [Brauers et al., 1996] appears to depend upon an erroneous $\mathrm{O}_{2}$ cross section. This error translates directly into an error in the calibration of the LIF experiment (EQ1).

Because of the above discrepancy we measured the $\mathrm{O}_{2}$ cross section using a pen ray $\mathrm{Hg}$ lamp with a flowing $\mathrm{N}_{2}^{2}$ purge. We used a CsI photomultiplier tube (which is insensitive to the strong $2537 \AA \mathrm{Hg}$ line) equipped with an interference filter to measure the attenuation of the $1849.5 \AA$ $\mathrm{Hg}$ line as a function of $\mathrm{O}_{2}$ pressure. As we increased the optical depth, however, the calculated cross section decreased continuously. Similar behavior has been observed elsewhere [Cantrell et al., 1997].

To investigate this further, we took a high resolution $(0.013 \AA)$ spectrum of the $\mathrm{Hg}$ lamp on the HarvardSmithsonian 6.65 meter vacuum-ultraviolet spectrometer. Details of the experimental apparatus are given in Yoshino et al., [1983]. The lamp was purged with $\mathrm{N}_{2}$ for cooling and to prevent ozone formation. The spectrometer provides an absorption path $\sim 1300 \mathrm{~cm}$ long. During the experiment we varied the amount of $\mathrm{O}_{2}$ in the spectrometer, and the lamp operating conditions. Figure 1(a) shows an expanded portion of $\sigma_{\mathrm{O}_{2}}$ in the $(8,0)$ Schumann-Runge (S-R) band [Yoshino et al., 1992] superposed with the Hg lamp spectrum measured with the spectrometer evacuated. The spectrum shows that the pen ray lamp is not a line source. The transition is selfreversed, significantly broadened, and asymmetric, with a long tail to the red. The saturation effects observed are clearly understandable: $\sigma_{\mathrm{O}_{2}}$ is significantly higher for the portion of the lamp spectrum at shorter wavelength. This is illustrated in Figure 1(b). With the addition of $\sim 4.2 \times 10^{19}$ molec/cm $\mathrm{O}_{2}$ to the spectrometer $(\sim 1$ torr $)$, most of the attenuation is at the center of the $S-R$ lines. Addition of $\sim 3.4 \times 10^{20} \mathrm{molec} / \mathrm{cm}^{2}$ oxygen (about 8 torr) shows depletion of the lamp spectrum in the region of the S-R bands to essentially the dark count base line of the photomultiplier tube. However, absorption due to the unsaturated $\mathrm{O}_{2}$ lines between $1849.5 \AA$ and $1850.0 \AA$ is still visible. Note that the absorption seen in the 1 torr data allows us to align the wavelength of the $\mathrm{Hg}$ lamp source with the oxygen absorption

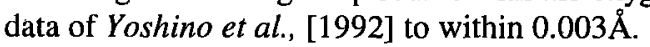

The effective $\mathrm{O}_{2}$ cross section for the lamp is determined from the $\mathrm{O}_{2}$ absorption spectrum of Yoshino et al., [1992] weighted by the $\mathrm{Hg}$ emission spectrum observed at the spectrometer exit: 


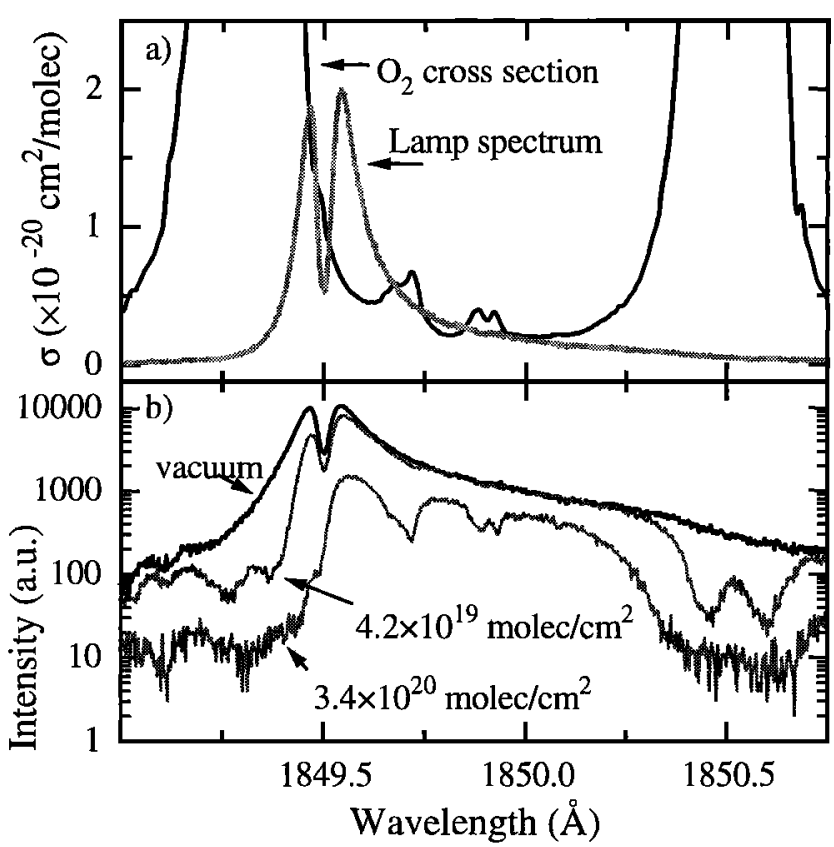

Figure 1. (a) Expanded portion of the oxygen absorption cross section [Yoshino et al., 1992] superposed with the $\mathrm{Hg}$ spectrum measured with the spectrometer evacuated. (b) Spectrum for three different amounts of oxygen added to the spectrometer. The intensity is plotted on a log scale and the $\mathrm{O}_{2}$ concentration shown as optical path $\left(\mathrm{molec} / \mathrm{cm}^{2}\right)$.

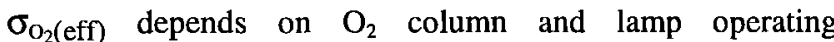
conditions, which will change the $\mathrm{Hg}$ emission spectrum. In addition, any error in $\sigma_{\mathrm{O}_{2}}(\mathrm{v})$ will translate directly into an

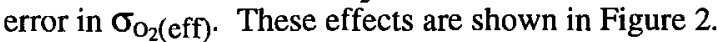

The inset of Figure 2 illustrates the effect of lamp conditions on the observed spectrum. Additional cooling added to the $\mathrm{Hg}$ lamp (trace $\mathrm{B}$ ) results in a reduction in spectral width by approximately $1 / 4$ relative to the lamp with

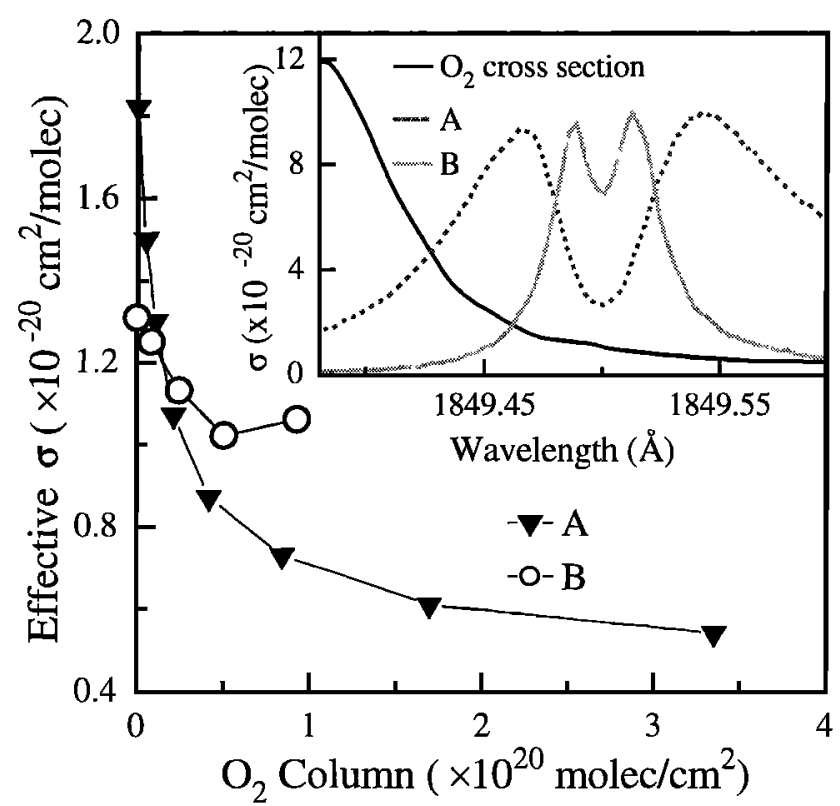

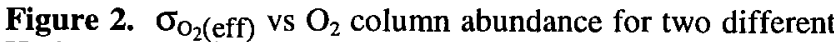
$\mathrm{Hg}$ lamp operating characteristics ( $\mathrm{A}$ and $\mathrm{B}$ ). The inset shows the $\mathrm{Hg}$ spectra superposed on the $\mathrm{O}_{2}$ absorption cross section [Yoshino et al., 1992]. The narrower linewidth seen in (B) is from the lamp with the plasma voltage reduced by $\sim 3$ and the $\mathrm{N}_{2}$ purge flow over the lamp dramatically increased relative to (A). The lamp intensity is in arbitrary units. less cooling (A). As expected, the self reversal in B is also

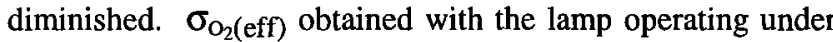
condition A shows a variation of a factor of 3 between when the spectrometer was evacuated and when a $1.0 \times 10^{20}$ molec $/ \mathrm{cm}^{2} \mathrm{O}_{2}$ optical path was present. $\sigma_{\mathrm{O}_{2} \text { (eff) measured }}$ with the $\mathrm{Hg}$ lamp operating under condition $\mathrm{B}$ shows a variation of $30 \%$ over the same range. In either case, it is clear that the use of a literature value for the oxygen cross section at $1849.5 \AA$ is not appropriate for a pen ray lamp.

The effective cross section depends upon both the lamp conditions and the $\mathrm{O}_{2}$ concentration between the lamp and the photolysis region. The lamp we used illustrates the general problem, and its characteristics may not be the same as lamps in other experiments. Thus, any attempt to determine an effective cross section using the results in Figure 2 is inappropriate; direct measurement of $\sigma_{\mathrm{O}_{2}(\mathrm{eff})}$ under field conditions is essential.

Acknowledgements. We thank Dr. Kouichi Yoshino of the Harvard-Smithsonian Center for Astrophysics (H-SCfA) for use of the vacuum ultraviolet spectrometer and for his expertise. The $O_{2}$ cross sections were obtained from the H-SCfA web site: http://cfawww.harvard.edu/amp/data/S-R.html. We thank NASA's Upper Atmospheric Research Program for support.

\section{References}

Aschmutat, U., et al., A tunable source of hydroxyl $(\mathrm{OH})$ and hydroperoxy $\left(\mathrm{HO}_{2}\right)$ radicals: In the range between $10^{6}$ and $10^{9}$ $\mathrm{cm}^{-3}$, in Physico-Chemical Behaviour of Atmospheric Pollutants, edited by G. Angeletti and G. Restilli, pp.811-816, European Commission, Brussels, 1994.

Brauers, T., et al., Intercomparison of tropospheric $\mathrm{OH}$ radical measurements by multiple folded long-path laser absorption and laser induced fluorescence, Geophys. Res. Lett., 23, 2545, 1996.

Cantrell, C.A., et al., Absorption cross sectons for water vapor from 183 to 193 nm, Geophys.Res. Lett., 24, 2195-2198, 1997.

Dorn, H.-P., et al., In-situ detection of tropospheric $\mathrm{OH}$ radicals by folded long-path laser absorption. Results from the POPCORN field campaign in August 1994, Geophys. Res. Lett., 23, 25372540,1996

Hofzumahaus, A., et al., The measurement of tropospheric $\mathrm{OH}$ radicals by laser-induced fluorescence spectroscopy during the POPCORN field campaign, Geophys. Res. Lett., 23, 2541, 1996.

Hudson, R. D., and L. J. Kieffer, Absorption cross sections of stratospheric molecules, The Natural Stratosphere of 1974, CIAP Monograph 1, pp. 5156-5194, 1975.

Reiner, T., M. Hanke, and F. Arnold, Atmospheric peroxy radical measurements by ion molecule reaction-mass spectrometry: A novel analytical method using amplifying chemical conversion to sulfuric acid, J. Geophys. Res., 102, 1311-1326, 1997.

Schultz M., et al., Calibration source for peroxy radicals with built-in actinometry using $\mathrm{H}_{2} \mathrm{O}$ and $\mathrm{O}_{2}$ photolysis at $185 \mathrm{~nm}, J$. Geophys. Res., 100, 18,811-18,816, 1995.

Washida, N., Y. Mori, and I. Tanaka, Quantum yield of ozone formation from the photolysis of the oxygen molecule at 1849 and $1931 \AA$ A. J. Chem. Phys., 54,1119-1122, 1971.

Yoshino, K., et al., High resolution absorption cross section measurements and band oscillator strengths of the $(1,0)-(12,0)$ Schumann-Runge bands of $\mathrm{O}_{2}$, Planet. Space Sci., 31, 339, 1983.

Yoshino, K., et al., High resolution absorptıon cross sections in the transmission window region of the Schumann-Runge bands and Herzberg continuum of $\mathrm{O}_{2}$, Planet. Space Sci., 40, 185-192, 1992.

E. J. Lanzendorf, T. F. Hanisco, N. M. Donahue, and P. O Wennberg, Department of Chemistry, Harvard University, Cambridge, MA 02138. (e-mail: lanzendorf@huarp.harvard.edu; )

(Received March 11, 1997; revised August 6, 1997; accepted October 8, 1997.) 